\title{
An Association between Fimbriae and Pores in the Wall of Fusiformis nodosus
}

\author{
By R. C. HAMILTON, F. G. BOVER AND T. J. MASON \\ Commonwealth Serum Laboratories, Parkville, Victoria 3052, Australia \\ (Received 7 April 1975; revised 7 July 1975)
}

INTRODUCTION

Both Stewart (1973) and Walker et al. (1973) have shown that Fusiformis nodosus is frequently fimbriated. Since the discovery of fimbriae by Houwink \& van Iterson (1950), little has been reported on the association of these organelles with the walls of bacteria. During an ultrastructural study of the antigens of $F$. nodosus we observed the manner in which the fimbriae pass through the wall of this organism.

\section{METHODS}

Fusiformis nodosus strains 198, 205 and 21 7, originally obtained from C.S.I.R.O. McMaster Laboratory culture collection, were used. The organisms were stored at $4{ }^{\circ} \mathrm{C}$ or $-60{ }^{\circ} \mathrm{C}$, as freeze-dried preparations in ampoules.

Cultures were incubated overnight at $37^{\circ} \mathrm{C}$ under anaerobic conditions. The medium contained (g/l): peptone, 50; yeast extract, 2 ; L-arginine, $3 \cdot 5 ; \mathrm{L}$-lysine, $\mathrm{I} \cdot 5 ; \mathrm{L}$-cysteine, I. Samples for electron microscopy were removed at intervals during the culture run.

A small drop of culture sample was placed on a Formvar-coated copper grid. After allowing the organisms to adsorb for about $30 \mathrm{~s}$, the excess fluid was removed with filter paper and the grid was inverted on to a drop of $2 \%(\mathrm{w} / \mathrm{v})$ sodium phosphotungstate solution $\mathrm{pH} 7 \cdot 0$. Thirty seconds later the grid was picked up, the excess stain removed with filter paper and the grid allowed to dry in air. When dry, the grid was immediately examined with a Siemens Elmiskop I electron microscope. Measurements were made from electron micrographs $(80000 \times)$. The microscope had been calibrated with a line grating replica having spacings of 2160 lines/mm (Polaron Equipment Ltd, London) and also with negatively stained catalase crystals (Wrigley, 1968). The dimensions given are the mean values of several measurements.

\section{RESULTS AND DISCUSSION}

Like Stewart (1973) and Walker et al. (1973), we observed that $F$. nodosus is frequently fimbriated (Fig. I $a$ ). The number of fimbriae varied from one bacterium to another, was affected by the age of the culture, and varied from culture to culture. Duplicate cultures did not always produce the same number of fimbriae, and in all cultures where fimbriae were present there were bacteria with no fimbriae. The fimbriae generally had a polar distribution, although on heavily fimbriated bacteria the distribution tended to become peritrichous. In cultures where fimbriae were present, we also observed 'pores' in many bacteria (Fig. $\mathrm{I} b, c$, $d$ ). Because of the greater contrast, these pores were more readily observed in lysed bacteria. The pores were $6 \cdot \mathrm{Imm}$ in diameter and were surrounded by a collar of material, $15.2 \mathrm{~nm}$ in diameter, which was less electron-dense under our conditions. The pores were not arranged 

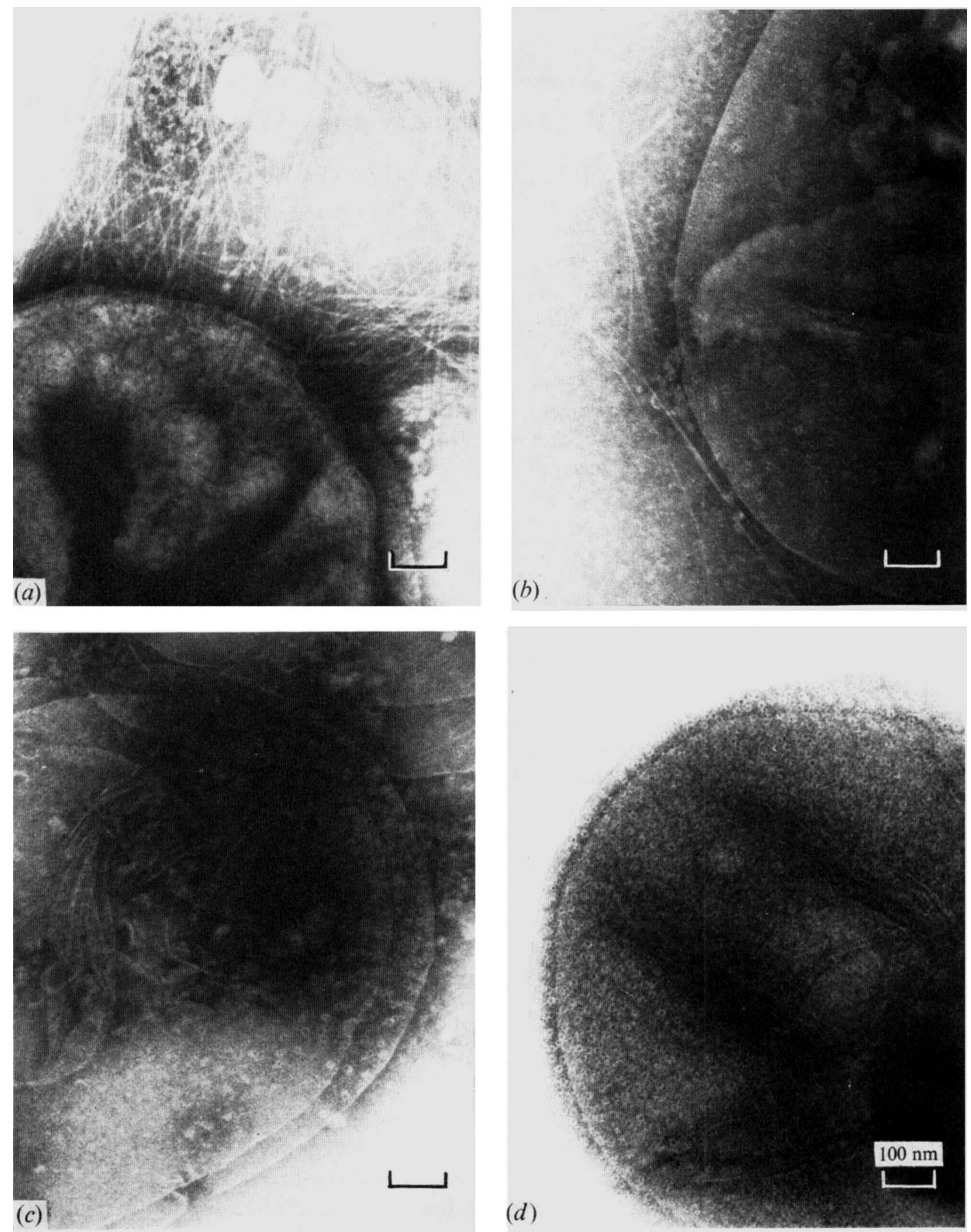

Fig. I. Fusiformis nodosus stained with sodium phosphotungstate. (a) Intact bacterium with numerous fimbriae. Note some pores where fimbriae have been detached. $(b)-(d)$ Lysed bacteria. Note varying number of pores per bacterium. 
in any particular geometric pattern over the surface of the organisms. There was no variation in appearance, of either the fimbriae or the pores, from strain to strain.

We believe that the pores are associated with the fimbriae, and are holes in the wall of the organism through which the fimbriae normally pass; the collars are 'grommet-like' structures which reinforce the wall where the fimbriae pass through. Evidence in support of our beliefs is as follows. In cultures where fimbriae were absent, pores were not observed. The pores had a distribution over the bacterial surface that was similar to that of the fimbriae. Though they were normally polar, they tended to become peritrichous when more numerous (Fig. I $b, c, d$ ). In cultures where there were only a few fimbriae per bacterium, there were only a few pores per bacterium (Fig. I $b$ ). The diameter of the pores, 6. I nm, was similar to the width of the fimbriae. Walker et al. (1973) described the fimbriae of $F$. nodosus as being approximately $6 \mathrm{~nm}$ in diameter, Stewart (1973) reported that their mean width was $4.6 \mathrm{~nm}$ (although the diameter varied along their length), and we measured that they were up to $6 \mathrm{~nm}$ in diameter. It was very difficult to demonstrate by negative staining fimbriae actually passing through the pores, because when fimbriae were present the pores were filled and no stain could penetrate and make them obvious. So far, we have been unsuccessful in demonstrating the fimbriae passing through the pores by the alternative method of thin sectioning. Walker et al. (1973) described the wall of $F$. nodosus as being typical of a Gram-negative bacterium. It consisted of a thin mucopeptide layer sandwiched between a cytoplasmic membrane and an outer membrane-like layer. We believe that the pores we observed were pores in the mucopeptide layer and that they can only be seen when the outer membrane-like layer, which would normally obscure them, is lost. Weiss \& Raj (1972) suggested that bacterial fimbriae arise from the cytoplasmic membrane and Poon \& Day (1975) similarly suggested that fungal fimbriae appear to arise from the cytoplasmic membrane or from under it. We do not know how the fimbriae arise from the cytoplasmic membrane as this retracts and becomes folded when the bacteria lyse (Fig. I $b, c, d$ ).

Although similar pores have been described by Swanson, Kraus \& Gotschlich (1971) in a study of the fimbriae of Neisseria gonorrhoeae, there was no suggestion that they were channels through which the fimbriae normally pass. In Fig. I I of the paper of Hoeniger (1965) on Proteus mirabilis, and Fig. 2 of the paper of Weiss \& Raj (1972) on Pseudomonas aeruginosa, pores can be observed although they are not commented on in the text. Our suggestion that the collars act as grommets, i.e. local reinforcements of the wall to support the fimbriae, is similar to the suggestion by Betz (1969) that there are flagella grommets in Clostridium sporogenes. We believe that the pores and their collars, which we have described in $F$. nodosus, may be found whenever fimbriae are present on bacteria.

We thank R. J. Sikkes and A. F. McDonald for their excellent technical assistance.

\section{REFERENCES}

BETz, J. V. (1969). Structure of the proximal ends of flagella of Clostridium sporogenes. Canadian Journal of Microbiology 15, 76I-764.

HoENIGER, J. F. M. (1965). Development of flagella by Proteus mirabilis. Journal of General Microbiology 40, 29-42.

Houwink, A. L. \& van ITERson, W. (1950). Electron microscopical observations on bacterial cytology. II. A study on flagellation. Biochimica et biophysica acta 5, I0-44.

Poon, N. H. \& DAY, A. W. (1975). Fungal fimbriae. I. Structure, origin and synthesis. Canadian Journal of Microbiology 21, 537-546.

STEWART, D. J. (1973). An electron microscopic study of Fusiformis nodosus. Research in Veterinary Science 14, 132-1 34 . 
Swanson, J., Kraus, S. J. \& Gotschlich, E. C. (197I). Studies on gonococcus infection. I. Pili and zones of adhesion: their relation to gonococcal growth patterns. Journal of Experimental Medicine 134, 886-906.

Walker, P. D., Short, J., Thomson, R. O. \& RoberTs, D. S. (1973). The fine structure of Fusiformis nodosus with special reference to the location of antigens associated with immunogenicity. Journal of General Microbiology 77, 35I-36I.

WeISS, R. L. \& RAJ, H. D. (1972). The structure and isolation of pili (fimbriae) of Pseudomonas aeruginosa. Australian Journal of Experimental Biology and Medical Science 50, 559-566.

WRIGLEY, N. G. (I 968). The lattice spacing of crystalline catalase as an internal standard of length in electron microscopy. Journal of Ultrastructure Research 24, 454-464. 